Conclusions: In all CTD, the capillaries in SSc patients are most severely damaged. The disease of capillaries in CTD patients correlates with PAH, ILD and cardiovascular complications. So, NVC could be a predictive detection method for $\mathrm{PAH}$ and cardiopulmonary disease in CTD patients.

Disclosure of Interest: None declared

DOI: 10.1136/annrheumdis-2018-eular.3187

\section{AB0557 HAEMATOLOGICAL INVOLVEMENT (CYTOPENIA) AT THE TIME OF THE DIAGNOSIS IS ASSOCIATED WITH LESS SEVERE OCULAR INVOLVEMENT IN PATIENTS WITH PRIMARY SJOGREN SYNDROME}

C.G. Buzatu, S. Daia-lliescu, I. Saulescu, D. Zaharia, C. Purice, T. Gudu, A. Borangiu, L. Groseanu, V. Bojinca, F. Berghea, A. Balanescu, D. Predeteanu, R. Ionescu, D. Opris-Belinski. Internal Medicine and Rheumatology, "SFANTA MARIA" Clinical Hospital, Carol Davila University of Medicine and Pharmacy, Bucharest, Romania

Background: In patients with primary Sjogren Syndrome (pSS), haematological involvement - autoimmune cytopenia, might be present at the time of the diagnosis or can develop in time after the characteristic glandular involvement. ${ }^{(1,2)}$ Objectives: The objective of the study is to evaluate the correlation between glandular involvement (ocular) and presence of cytopenia in patients diagnosed with pSS.

Methods: A retrospective analysis was performed on a cohort of patients diagnosed with primary Sjogren Syndrome under surveillance in one Rheumatology Centre between 2009 and 2016. The documented cases have been diagnosed according to the 2002 American-European Consensus group classification criteria, the 2012 ACR criteria or 2016 ACR/EULAR Classification Criteria for pSS. The EULAR Sjogren's Syndrome Disease Activity Index (ESSDAI) was calculated for all patients. Ocular assessment and follow-up were performed in collaboration with the same ophthalmologist. The data was analysed using Windows Excel/ SPSS20.0.

Results: 30 female patients diagnosed with pSS were included in the study. The mean age at the time of diagnosis was 52.1 years \pm SD 9.1. The ESSDAI was calculated for all patients at baseline: 5 (17\%) patients presented high disease activity (ESSDAI >14), $14(46 \%)$ patients moderate disease activity ( $5 \leq \mathrm{ESSDAI} \leq 13)$ and $11(37 \%)$ patients low disease activity (ESSDAI $<5)$. The domain weight for glandular involvement when calculating ESSDAI is fairly low (2), ${ }^{1}$ so in the studied group there wasn't obtained a statistically significant correlation between ocular involvement and disease activity as evaluated by ESSDAI.

In the clinical case series, Spearman's rank correlation coefficient between haematological (autoimmune cytopenia), and biological markers (hypocomplementemia) and ocular involvement were calculated. A strong negative correlation was found between autoimmune cytopenia and glandular manifestations (ocular involvement-xerophthalmia) $(r=-0,60 ; p<0,05)$. Another strong negative correlation was obtained between hypocomplementemia and severe ocular involvement (corneal ulceration) $(r=-0,59, p<0,05)$, respectively.

Conclusions: Patients diagnosed with primary Sjogren Syndrome that presented at disease's onset cytopenia and hypocomplementemia had a less severe ocular involvement.

\section{REFERENCES:}

[1] Seror R, Theander E, Brun JG, et al, Validation of EULAR primary Sjögren's syndrome disease activity (ESSDAI) and patient indexes (ESSPRI) Annals of the Rheumatic Diseases 2015;74:859-866.

[2] Shiboski CH, Shiboski SC, Seror R, Criswell LA, Labetoulle M, Lietman TM, Rasmussen A, Scofield H, Vitali C, Bowman SJ, Mariette X, International Sjögren's Syndrome Criteria Working Group, Ann Rheum Dis. 2017 Jan;76(1):9-16.

[3] Koh JH, Lee J, Chung SH, Kwok SK, Park SH, Relation of Autoimmune Cytopenia to Glandular and Systemic Manifestations in Primary Sjögren Syndrome: Analysis of 113 Korean Patients, J Rheumatol. 2015 Oct;42 (10):1817-24.

Disclosure of Interest: None declared

DOI: 10.1136/annrheumdis-2018-eular.7189

\section{AB0558 ARE REGULATORY T CELL LEVELS DIFFERENT IN ACTIVE AND INACTIVE SLE PATIENTS?}

H. Üsküdar Teke1, D. Üsküdar Cansu' ${ }^{2}$, C. Bal ${ }^{3}, \underline{\text { C. Korkmaz }}{ }^{2} .{ }^{1}$ Internal Medicine, Hematology; ${ }^{2}$ Internal Medicine, Rheumatology; ${ }^{3}$ Biostatistics, Eskişehir Osmangazi University, Eskişehir, Turkey

Background: The subgroups of T helper cells and regulatory T cells (T-reg) are involved in the pathogenesis of systemic lupus erythematosus (SLE). T-reg cells suppress immune response to autoantigens and prevent autoimmune diseases (AID). Although there are studies suggesting that Treg cells are reduced during the active period of SLE, there are also studies claiming reversal.

Objectives: To determine whether there is a difference between T-reg and Th-17 cell levels in active and inactive SLE patients and to demonstrate the effects of these cells on disease course.

Methods: 21 SLE patients without active infection were included. Erythrocyte sedimentation rate, CRP, C3, C4, anti-ds-DNA levels, SLEDAl values were recorded in terms of organ and system involvement, hemogram results, disease activation. SLEDAI $\geq 6$ were considered active disease. Concurrent peripheral blood Th17 and T-reg levels were studied. 15 healthy control subjects were included in the study.

Results: 19 of the patients were women, the mean age was $37.3 \pm 12.9$ years and mean duration of the disease was $7.9 \pm 1.29$ years. Hematologic involvement was present in $15(71.4 \%)$ of the patients, renal involvement in $17(81 \%)$ and joint involvement in 7 (42.9\%). Both Treg cells and CD4 + IL17+cell levels were significantly higher in SLE group than $\mathrm{HC}$ group in terms of CD4 +CD25+, CD4 +FOXP3+T reg, CD4 +CD25+FOXP3+T reg $(\mathrm{p}=0.011, \mathrm{p}=0.001, \mathrm{p}=0.001$ and $p=0.040$, respectively). There was no significant difference between active $(n=12$ and inactive $(n=9)$ SLE patients in terms of Th17 and T-reg levels. However, in the inactive period, the levels of CD4 +FOXP3+T reg and CD4 +CD25+FOXP3+Treg cells tended to increase compared to the active period.

Conclusions: This study showed the tendency of increasing in Treg cells in the inactive period. This may be related to the modification of immunosuppressive drugs. It may be more appropriate to perform similar studies before and after treatment.

Disclosure of Interest: None declared

DOI: 10.1136/annrheumdis-2018-eular.6151

\section{AB0559 THE PREVALENCE OF NON-CRITERIA ANTI- PHOSPHOLIPID ANTIBODIES IN ANTI-PHOSPHOLIPID SYNDROME}

C. Li ${ }^{1}$, L. Zhu ${ }^{1}$, Z. Wang ${ }^{1}$, Y. Sun ${ }^{2}$, R. Mu ${ }^{1}$, Z. Li . ${ }^{1}$ Peking University People's Hospital, Beijing; ${ }^{2} 266$ Hospital of Chinese People's Liberation Army, Chengde, China

Background: Antiphospholipid syndrome (APS) is an autoimmune disease characterised mainly by arterial and/or venous thrombosis, recurrent pregnancy morbidity, with the presence of a variety of heterogeneous circulating antiphospholipid antibodies. However, there are a group of APS patients with persistently negative antiphospholipid antibodies. It is necessary to validate new spe cific antibodies to better recognition of these APS patients.

Objectives: To explore the clinical significance of non-criteria anti-phospholipid antibodies in a large cohort of Chinese patients with anti-phospholipid syndrome (APS).

Methods: Serum samples were obtained from 214 APS patients, 122 disease control including systemic lupus erythematosus, sjogren syndrome, ankylosing spondylitis, rheumatoid arthritis, osteoarthritis and 50 healthy control. Antiphos phatidylserine $(\lg \mathrm{A} / \lg \mathrm{G} / \operatorname{lgM})$ (aPS), anti-phosphatidylethanolamine (IgA/lgG/lgM) (aPE), anti-prothrombin-antibodies (IgA/lgG/lgM) (aPT) , anti-annexin V-antibodies (IgA/lgG/lgM) (aAnxV), anti-phosoholipid-antibody ( $\lg G / \operatorname{lgM})(\mathrm{aPL})$, anti-oxLDL antibody $(\lg G / \lg M)($ aoxLDL) were tested by ELISA kits(HUMAN Diagnostics Prod ucts, Germany) and lgG/lgM APhL were tested by ELISA(Louisville APL Diagnostic, USA). The Chi-square $\left(\chi_{2}\right)$ test was used to examine the difference of frequencies of antibodies in APS patients and patients with other diseases. Spear man correlation analysis was performed to investigate the relationship between aPS/PT and other clinical/laboratory parameters.

Results: The prevalence of aPS IgG, aPS lgM, aPT, aPE, aAnxV, aPL, aoxLDL and IgG APhL, IgM APhL were 44.8\%, 22.4\%, 46.3\%, 9.8\%, 17.8\%, 44.4\%, $22.4 \%, 45.3 \%$ and $22.9 \%$. The specificity of the antibodies were $82.6 \%, 95.3 \%$, $96.0 \%, 99.4 \%, 95.3 \%, 92.4 \%, 87.2 \%, 95.3 \%$ and $94.8 \%$. The highest positive predictive values of these antibodies were aPE. aPE, aPS IgM and APhL IgM were associated with thrombotic events and oxLDL, aPE, aPL, aPS IgG, aPS IgM, aPT, aoxLDL, APhL IgG and APHL IgM were correlated with anti-cardiolipin antibody (ACL). aPL, aPS IgG, aPS IgM, aPT, APhL IgG and APhL IgM were associated with $\beta 2-G P 1$ antibody. APhL $\lg$, APhL $\lg M$ and $P S \lg G$ were the highest prevalence in both $A C L$ and lupus anticoagulant (LAC) negative patients. APT has the highest prevalence in ACL and $\beta 2-G P 1$ negative patients and APhL $\operatorname{lgG}$ and aPS IgG were the highest two antibodies in LAC and $\beta 2-G P 1$ negative patients and aPT has the highest prevalence in seronegative APS patients.

Conclusions: Non-criteria aPLs have a good diagnostic value in APS and were associated with thrombotic events.

\section{REFERENCES:}

[1] Hughes GR, Khamashta MA (2003) Seronegative antiphospholipid syndrome. Ann Rheum Dis 62:1127 
[2] Examining the prevalence of non-criteria anti-phospholipid antibodies in patients with anti-phospholipid syndrome: a systematic review.Rheumatology 2015;54:2042-2050.

[3] A unique antiphospholipid assay recognizing phospholipid mixture compared with criteria antiphospholipid immunoassays in lupus patients. Lupus 2017;26(6):606-615.

Acknowledgements: We thank all patients and healthy donors whom took part in this study.

Disclosure of Interest: None declared

DOI: 10.1136/annrheumdis-2018-eular.6750

\section{AB0560 1 PATIENTS WITH RHEUMATOID ARTHRITIS AND LUPUS HAVE SIMILAR PREVALENCE OF PERIODONTITIS - A CROSS-SECTIONAL SURVEY}

C. Ciurtin $^{1}$, M. Orlandi ${ }^{2}$, J. Bakshi ${ }^{1}$, J. Guinto ${ }^{1}$, B. Bernstein ${ }^{1}$, F. D’Aiuto ${ }^{1}$

${ }^{1}$ Rheumatology, University College London; ${ }^{2}$ Oral Health, Eastman Dental Hospital, London, UK

Background: Periodontitis (PD) is a chronic inflammatory disease of the gingival tissues triggered by a dysbiotic microflora and causing the loss of soft and hard tissues surrounding the dentition. Over the last two decades, PD has been linked to a systemic inflammatory response and an increased risk of other comorbidities including cardiovascular diseases and diabetes. Numerous observational studies have confirmed an association between PD and rheumatic diseases. Some evidence suggests an association with rheumatoid arthritis (RA) and a beneficial effect of periodontal treatment on RA outcomes. Scarce evidence instead exists on the association between PD and Systemic Lupus Erythematosus (SLE). The main aim of this study was to evaluate the prevalence of PD in RA and SLE.

Methods: We conducted a cross-sectional survey of consecutive eligible outpatients with RA and SLE attending the Rheumatology Department at UCLH. PD diagnosis was estimated administering a validated self-reported questionnaire. Medical histories, cardiometabolic risk factors and assessment of standard biomarkers of inflammation and RA activity were collected as part of the outpatients' visit.

Results: 86 patients affected by RA and 122 by SLE and 5 presenting both diseases were recruited and agreed to complete the questionnaire. PD was detected in 100 patients of the overall survey (47\%). 38 (44\%) patients with RA and 59 (48\%) patients with SLE had prevalent PD. There was no statistically significant difference in the prevalence of PD between the two patients' groups $(p=0.575)$. PD was associated with diagnosis of diabetes $(p=0.023)$, hypertension $(p=0.004)$ and hypercholesterolemia $(p<0.0001)$. Diagnosis of PD was associated with increased levels of C-reactive protein (CRP) $(2.8 \pm 3.3$ vs $4.0 \pm 4.4, p=0.03)$ in the whole population. In RA patients PD was associated with increased CRP (3.2 \pm 3.2 vs $5.2 \pm 4.4, p=0.014)$ and $E S R(9.8 \pm 10.0$ vs $18.3 \pm 16.6, p=0.008)$.

Conclusions: Prevalence of PD is similar in both RA and SLE (approximately $45 \%$ ) and to the UK national estimates (Adult Dental Survey 2009). PD could contribute to an increased inflammatory profile in patients with RA and SLE. Our data highlight the need of assessing oral health needs of patients with rheumatic diseases.

Disclosure of Interest: None declared

DOI: 10.1136/annrheumdis-2018-eular.2532

\section{AB0561 INFECTIONS IN NEWLY DIAGNOSED SPANISH PATIENTS WITH SYSTEMIC LUPUS ERYTHEMATOSUS: DATA FROM THE RELES COHORT}

C. Gonzalez-Echavarri ${ }^{1}$, M. García ${ }^{2}$, G. Espinosa ${ }^{3}$, G. Ruiz-Irastorza ${ }^{1}$, on behalf of Autoimmune Diseases Study Group GEAS. ' Autoimmune Diseases Unit. Internal Medicine Deparment, BioCruces Health Research Institute. Cruces University Hospital; ${ }^{2}$ Autoimmune Diseases Unit. Internal Medicine Department, Cruces University Hospital, BILBAO; ${ }^{3}$ Department of Autoimmune Diseases, Hospital Clinic, Barcelona, Spain

Background: Infections continue to be an important source of morbidity and mortality in systemic lupus erythematosus (SLE). ${ }^{1}$ Susceptibility to infections is thought to be due to a combination of disease related factors and immunosuppression, however differential contributions during disease course has not been yet studied.

Objectives: Using data of patients from the longitudinal inception cohort Registro Español de Lupus Eritematoso Sistémico (RELES), we aimed to analyse how predictors of infection change during the course of the disease. ${ }^{2}$

Methods: Two hundred and eighty-two patients from the RELES cohort were included. Markers of lupus activity, average prednisone doses and use of immunosuppressive drugs were compared between patients with and without infections within the first and second year of disease. For the analysis, drugs given during the first month of follow-up were considered for infections during the first year and medications given during the first year were considered for infections during the second. ${ }^{3}$

Results: Nineteen patients $(6.4 \%)$ had a documented episode of infection during the first year of follow-up and 16 patients $8(5.67 \%)$ during the second. The following variables were associated with infections during the first year: hypocomplementemia at diagnosis $(p=0.01)$, nephritis at diagnosis $(p=0.03)$, SLEDAI score $(p<0.01)$, average dose of prednisone higher than $30 \mathrm{mg} /$ day $(p=0.01)$, methylprednisolone pulses $(p=0.05)$ and mycophenolate use $(p=0.02)$. The independent variables in the final model were hypocomplementemia (OR $4.41,95 \% \mathrm{Cl} 0.96$ 20.2 ) and average dose of prednisone higher than $30 \mathrm{mg} /$ day (OR 6.60, 95\% Cl 1.3-32.4). The following variables were predictors of infections during the second year in the univariate analysis: average dose of prednisone higher than $7.5 \mathrm{mg} /$ day $(p=0.05)$, methylprednisolone pulses $(p=0.07)$, duration of therapy with antimalarials $(p=0.09)$, mycophenolate use $(p=0.01)$ and cyclophosphamide use $(p=0.05)$. The independent variables in the final model were average dose of pre dnisone higher than $7.5 \mathrm{mg} /$ day $(\mathrm{OR} 4.5,95 \% \mathrm{Cl} 0.99-21)$ and duration of therapy with antimalarials as a protective factor (OR $0.99,95 \% \mathrm{Cl} 0.99-1.00$ ).

Conclusions: Patients with high baseline activity are at a higher risk of infection during the first months but intensive lupus therapy, specifically with medium-high doses of prednisone, is the strongest predictor of infectious events. Continued use of antimalarials protects from infections.

\section{REFERENCES:}

[1] Danza A., Ruiz-Irastorza G. Infection risk in systemic lupus erythematosus patients: susceptibility factors and preventive strategies. Lupus. 2013 Oct:22(12):1286-94

[2] Ruiz-Irastorza, et al. Patterns of drug therapy in newly diagnosed Spanish patients with systemic lupus erythematosus. Clin Exp Rheumatol. 2016 May-Jun;34(3):466-72

[3] Ruiz-Irastorza, et al. First month prednisone dose predicts prednisone burden during the following 11 months: an observational study from the RELES cohort. Lupus Sci Med. 2016 Aug 2;3(1)

Disclosure of Interest: None declared

DOI: 10.1136/annrheumdis-2018-eular.6475

\section{$\mathrm{AB} 0562$ \\ EXTRAGLANDULAR MANIFESTATIONS IN PATIENTS WITH PRIMARY SJÖGREN SYNDROME IN A TERTIARY HOSPITAL IN MADRID}

C.M. Pijoan Moratalla, C. Sobrino-Grande, C. De la Puente-Bujidos.

Rheumatology, Hospital Ramón y Cajal, Madrid, Madrid, Spain

Background: Primary Sjögren syndrome (pSS) is a chronic autoinmune disorder characterised by generalised dryness. In a variable percentage of cases (up to $50 \%$ ) patients can present extraglandular disease, which frequently determines the prognosis.

Objectives: To determine the frequency of both glandular and extraglandular disease in patients with SSp seen in a tertiary hospital in Madrid and to compare them with the frequency observed in the large cohorts (SER and EULAR).

Methods: A descriptive, observational cross-sectional study was conducted. We included patients with diagnosis of pSS according to the ACR/EULAR Classification criteria (2016) attended in our Rheumatology Unit from 2012 to 2017. A database was created, including clinical and epidemiological data and a descriptive analysis was carried out comparing the results with those obtained in the SjögrenSER proyect and EULAR group.

Results: 106 patients with pSS were included. $92.5 \%$ were female (98), with a mean age at diagnosis of 45 years (range: $32-58$ ). Frequency of exocrine gland disease is shown in table 1. Dry eye was the most frequent symptom (91\%), with nearly half of them presenting ocular complications. $69.8 \%$ complained of dry mouth and $18.9 \%$ associated complications such as dysphagia and oral candidiasis. 16 patients (15\%) suffered from recurrent parotiditis and $13(12.3 \%)$ from salivary gland enlargement. Glandular disease also included xerosis (25\%), dyspareunia (11.3\%), upper respiratory tract dryness $(12.3 \%)$ and atrophic chronic gastritis (14\%). Frequency of extraglandular disease is shown in table 2. Chronic fatigue was the most frequent symptom, similar to the observed in both cohorts $(50.9 \%)$, followed by arthralgia which was less frequent than in the Spanish cohort (40.6\% vs $34.5 \%)$. 35 patients suffered from inflammatory arthritis and 3 cases associated fibromyalgia, less than the expected $(2.8 \%$ vs $14.6 \%$ and $22 \%-33 \%$ ). Sixteen patients suffered from interstitial lung disease, this being higher than the observed in both cohorts (15.1\% vs $6.64 \%$ and $5 \%$ ). Fewer patients suffered from depression compared with the EULAR group (24.5\% vs $40 \%$ ). Both peripheral neuropathy and renal disease were diagnosed in a percentage of patients similar to the expected $(11.3 \%$ vs $8.92 \%$ y $1.88 \%$ vs $1.83 \%$ respec tively). 7 patients had autoimmune thyroid disease. Finally, 5 patients $(4.7 \%)$ developed lymphoma, 3 of them being MALT lymphoma of the parotid gland 